\title{
Tracking of optic axis with an acousto-optically diffracted beam: generation of vector-vortex beam in triglycine sulfate crystals
}

\author{
Krupych O., Kostyrko M., Adamenko D., Skab I. and Vlokh R. \\ O.G. Vlokh Institute of Physical Optics, 23 Dragomanov Street, 79005 Lviv, Ukraine
}

Received: 22.01 .2020

\begin{abstract}
We analyze acousto-optic interactions for the case when a divergent diffracted optical beam propagates along one of the optic axes in biaxial crystals. We demonstrate that the diffracted beam reveals a specific spatial distribution of polarization states and transfers an optical vector-vortex field. It can be referred to as an optical vector-vortex beam with inseparable polarization and spatial states. At least intra-system entanglement occurs between different degrees of freedom, which are represented by the spin and orbit angular momentums in our case. The spatial orientation of the beam can be controlled while changing the angle between the optic axes. This is achieved by tuning the wavelength of optical radiation and the acoustic wave frequency. We have performed basic calculations using a particular example of optically biaxial triglycine sulfate crystals and assuming that the initial acoustic wave frequency amounts to $50 \mathrm{MHz}$ and the light wavelength changes from 400 to $675 \mathrm{~nm}$. Then the resulting acoustic frequency can increase up to $133 \mathrm{MHz}$ for the longitudinal acoustic mode and $93 \mathrm{MHz}$ or $89 \mathrm{MHz}$ for the two transverse modes. In other words, one can build a generator of optical vortices and operate their spatial orientation, using triglycine sulfate.
\end{abstract}

Keywords: optical vortex operation, vector vortex field, biaxial crystals, quantum entanglement

UDC: $535.52,621.37$

\section{Introduction}

Studies of peculiarities of acousto-optic (AO) diffraction in the vicinity of optic axes in biaxial crystals have started only recently. As an example, a collinear AO interaction in gyrotropic crystals has been investigated theoretically in the works [1, 2]. The studies $[3,4]$ have been devoted to the AO Bragg diffraction under conditions of light propagation close to one of the optic axes. It has been shown that, using this $\mathrm{AO}$ interaction type, one can construct ultra-wide-aperture and ultra-wideband acousto-optic deflectors to control optical radiation. In addition, it becomes possible to implement multiple devices on the same AO cell. Notice that the outlets of optic axes in the biaxial crystals represent topological defects of the cross sections of optical indicatrix orientation, with the defect strength being equal to $1 / 2$ [5] for a divergent beam propagating along the optic axis. Such a defect enables generation of a singly charged optical vortex (OV) whenever a circularly polarized conical optical beam propagates along one of the optic axes $[6,7]$ and a vector beam appears under conditions of conical refraction [8]. The above effects arise since the refractive-index surfaces in the vicinity of optic axes have a specific configuration, which generates a topological defect of the cross section of optical indicatrix orientation along the opticaxis direction.

It is natural to assume that the effects mentioned above can also manifest themselves under the conditions of AO Bragg diffraction, when the diffracted beam propagates along one of the optic axes. On the other hand, the optic-axis direction in the biaxial crystals depends on the wavelength of optical

Ukr. J. Phys. Opt. 2020, Volume 21, Issue 1 
radiation. This enables one to develop a spatially tunable OV generator. Here the main idea consists in using the AO Bragg interaction in order to direct the diffracted optical beam along the optic axis in a biaxial crystal. When we change the frequency of the acoustic wave (AW), the Bragg matching condition is satisfied for a different diffraction angle. By adjusting properly the AW frequency for every light wavelength, we could achieve a situation when the diffracted beam is directed exactly along the optic axis at this wavelength. As a result, we can control the OV propagation direction. In the present work we consider this problem on a particular example of triglycine sulfate crystals.

\section{Results}

We have performed our calculations on the example of monoclinic triglycine sulfate (TGS) crystals. The TGS crystals have the chemical formula $\left(\mathrm{NH}_{2} \mathrm{CH}_{2} \mathrm{COOH}\right)_{3} \mathrm{H}_{2} \mathrm{SO}_{4}$. They represent a well-known ferroelectric material with the monoclinic point symmetry group 2 under normal conditions and the group $2 / \mathrm{m}$ above the Curie temperature $T_{C}=322 \mathrm{~K}=49^{\circ} \mathrm{C}$ [9]. TGS is optically biaxial, with the principal refractive indices equal to $n_{x}=n_{g}=1.591, n_{y}=n_{p}=1.488$ and $n_{z}=n_{m}=1.563$ at the wavelength $\lambda=633 \mathrm{~nm}$ [10]. It is transparent from $0.24 \mu \mathrm{m}$ in the ultraviolet up to about $1.6 \mu \mathrm{m}$ in the infrared spectral range [11]. The crystallographic coordinate system $a b c$ (with $b$ axis being parallel to the two-fold symmetry axis) for the monoclinic TGS crystals is not rectangular. The monoclinic angle is relatively large, $\beta \approx 105^{\circ}$ [12]. When determining such physical quantities as elastic stiffness, compliance or piezoelectric coefficients, researchers usually use the Cartesian (or so-called crystal physical) coordinate system $X_{1} X_{2} X_{3}$, which is defined according to the rules $X_{2}\left\|b, X_{3}\right\| c$ and $X_{1} \perp b c$ [13]. In general, the principal axes $X, Y$ and $Z$ of optical indicatrix ellipsoid in the monoclinic crystals are not parallel to the $X_{1}, X_{2}$ and $X_{3}$ axes. In the particular case of TGS, the coordinate system $X Y Z$ is rotated with respect to the $X_{1} X_{2} X_{3}$ system by $3^{\circ}$ around the $Y=X_{2}=b$ axis (at the light wavelength $\lambda=633 \mathrm{~nm}$ ).

In the present work we make use of the optical-indicatrix coordinate system $X Y Z$, since the AO interactions are considered in the plane of optic axes. Fortunately, the tensor of elasticstiffness coefficients for this system has been earlier calculated in Ref. [14]. We will use it when computing the velocities of acoustic modes involved into the AO diffraction.

The both optic axes in the TGS crystals lie in the $X Z$ plane, with the $Z$ axis being the bisector of the acute angle $2 \mathrm{~V}$ between the optic axes. The dispersions of the $2 \mathrm{~V}$ angle and the refractive indices for TGS have been presented in the work [15] for the visible region $(\lambda=400-675 \mathrm{~nm})$ and the normal conditions. Basing on the above data, we have calculated the angle $\chi$ between the $X$ axis and the optic axis $\left(\chi=90^{\circ}-V\right)$ and have obtained the boundary values $\chi_{0}=\chi(400 \mathrm{~nm})=58.892^{\circ}$ and $\chi_{1}=\chi(675 \mathrm{~nm})=59.106^{\circ}$.

Let us assume that the initial AW frequency is equal to $f_{0}=50 \mathrm{MHz}$ and the Bragg condition is satisfied for the light wavelength $\lambda_{0}=400 \mathrm{~nm}$. It is known that the Bragg angle $\beta$ could be calculated using the relation

$$
\tan \beta=\frac{K}{2 k}=\frac{\lambda f}{2 n v}
$$

where $K, f$ and $v$ are respectively the wave number, the frequency and the velocity of the AW, $k$ and $\lambda$ are respectively the wave number and the wavelength of the incident light, and $n$ is the refractive index. Since we have accepted the condition $\beta \ll 1$, Eq. (1) can be rewritten as

$$
\beta \approx \frac{\lambda f}{2 n v} .
$$


It is clear from Eq. (2) that the Bragg angle is proportional to the AW frequency, and vice versa. Therefore the direction of the incident light (i.e., that of the wave vector $\mathbf{k}$ ) should be arranged in the way shown in Fig. 1. In this case we consider isotropic AO interaction with the incident and diffracted light waves polarized along the $Y$ axis. This means that the both optical beams have the same refractive index $n_{m}$ and the same wave number $k=k_{\mathrm{d}}=k_{\mathrm{m}}=2 \pi n_{\mathrm{m}} / \lambda$.

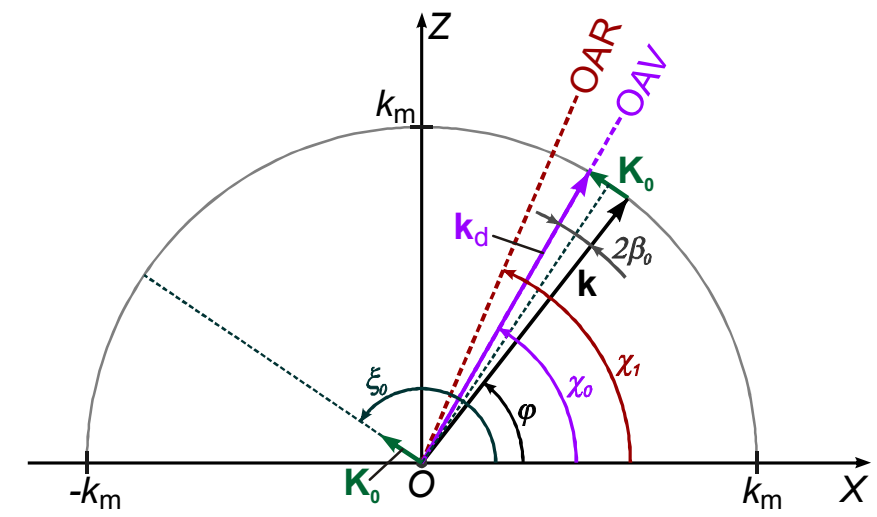

Fig. 1. Schematic representation of acousto-optic interaction occurring in the $X Z$ plane of TGS for the violet $(\lambda=400 \mathrm{~nm})$ light polarized along the $Y$ axis (normal to the plane of drawing). OAV and OAR are optic axes for the violet $(\lambda=400 \mathrm{~nm})$ and red $(\lambda=675 \mathrm{~nm})$ light waves; $\mathbf{K}_{\mathbf{0}}$, $\mathbf{k}$ and $\mathbf{k}_{\mathbf{d}}$ are wave vectors of the AW and the incident and diffracted light waves; $\beta_{0}$ is the Bragg angle, and $\varphi, X_{0}, X_{1}$ and $\xi_{0}$ denote azimuths of the incident light, for the violet and red light waves, and the AW vector, respectively.

As seen from the vector diagram depicted in Fig. 1, the azimuth of the AW vector $\mathbf{K}_{\mathbf{0}}$ is equal to $\xi_{0}=\chi_{0}-\beta_{0}+90^{\circ}$ for the violet light $(\lambda=400 \mathrm{~nm})$. Similarly, we have $\xi_{1}=\chi_{1}-\beta_{1}+90^{\circ}$ for the red light $(\lambda=675 \mathrm{~nm})$. In the case of TGS crystals, we obtain $\xi_{0}=148.77^{\circ}$ and $\xi_{1}=148.88^{\circ}$. It is obvious that these values are very close to each other, so that our further calculations for the acoustic velocities of the three different acoustic modes can be based upon the only (average) azimuth $\xi_{\mathrm{A}}=\left(\xi_{0}+\xi_{1}\right) / 2$. We have obtained $v_{\mathrm{QL}}\left(\xi_{\mathrm{A}}\right)=4858 \mathrm{~m} / \mathrm{s}$ for the quasi-longitudinal mode, and $v_{\mathrm{QT} 1}\left(\xi_{\mathrm{A}}\right)=2529 \mathrm{~m} / \mathrm{s}$ and $v_{\mathrm{QT2} 2}\left(\xi_{\mathrm{A}}\right)=2311 \mathrm{~m} / \mathrm{s}$ for the two quasi-transverse modes.

Now we need to write out the spectral dependence of the AW frequency, which provides propagation of the diffracted light along the optic axis inherent to some light wavelength. Basing on Eq. (2), we have

$$
f(\lambda)=\frac{2 v n_{m}(\lambda)}{\lambda} \beta(\lambda)=\frac{2 v n_{m}(\lambda)}{\lambda}\left[\beta_{0}+\Delta \beta(\lambda)\right]=f_{0}+\frac{2 v n_{m}(\lambda)}{\lambda} \Delta \beta(\lambda),
$$

where $\Delta \beta(\lambda)$ is the increment of the Bragg angle that arises from the changes from 400 to $675 \mathrm{~nm}$ in the light wavelength. To provide propagation of the diffracted beam along the optic axis specific to a given light wavelength, the increment of the Bragg angle should be equal to the spectral change of the optic-axis azimuth $\Delta \chi(\lambda)$ :

$$
\Delta \beta(\lambda)=\Delta \chi(\lambda)=\chi(\lambda)-\chi_{0} .
$$

The dispersion of the optic-axis azimuth increment $\Delta \chi(\lambda)$ has been calculated from the spectral dependence of the acute angle $2 V$ between the optic axes taken from Ref. [15] (see Fig. 2). The work [15] contains also the spectral dependence of the refractive index $n_{m}(\lambda)$, which has been used in our calculations.

Finally, the general spectral dependence of the acoustic frequency looks as

$$
f(\lambda)=f_{0}+\frac{2 v n_{m}(\lambda)}{\lambda} \Delta \chi(\lambda)
$$

Ukr. J. Phys. Opt. 2020, Volume 21, Issue 1 


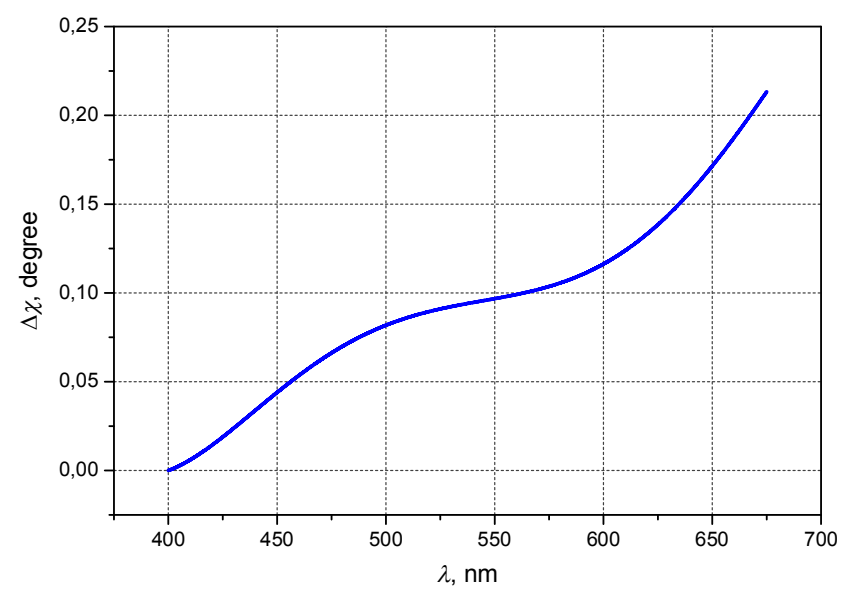

Fig. 2. Dispersion of optic-axis azimuth increment $\Delta X(\lambda)$ calculated for TGS crystals.

For each of the three AWs we obtain more specific formulae:

$$
\begin{aligned}
& f_{\mathrm{QL}}(\lambda)=f_{0}+\frac{2 v_{\mathrm{QL}}\left(\xi_{\mathrm{A}}\right) n_{m}(\lambda)}{\lambda} \Delta \chi(\lambda), \\
& f_{\mathrm{QT} 1}(\lambda)=f_{0}+\frac{2 v_{\mathrm{QT} 1}\left(\xi_{\mathrm{A}}\right) n_{m}(\lambda)}{\lambda} \Delta \chi(\lambda), \\
& f_{\mathrm{QT} 2}(\lambda)=f_{0}+\frac{2 v_{\mathrm{QT} 2}\left(\xi_{\mathrm{A}}\right) n_{m}(\lambda)}{\lambda} \Delta \chi(\lambda) .
\end{aligned}
$$

As a result, we have calculated the spectral dependences of the acoustic frequency for the three modes, which are presented in Fig. 3. For the starting acoustic frequency $50 \mathrm{MHz}$, we obtain the range of frequency changes up to $132.805 \mathrm{MHz}$ for the quasi-longitudinal mode and up to 93.107 MHz and 89.391 MHz for the two quasi-transversal modes. Then the spatial operation of OVs can be implemented with the TGS crystals, using the spectral tuning of their optic-axis orientation in the visible range $\lambda=400-675 \mathrm{~nm}$ and using the effect of AO diffraction. The central $\mathrm{AW}$ frequency $f_{\mathrm{C}}$ and the bandwidth $\Delta f$ of such a device are equal respectively to $f_{\mathrm{C}} \mathrm{QL}=91.4 \mathrm{MHz}$ and $\Delta f_{\mathrm{QL}}=41.4 \mathrm{MHz}$ for the quasi-longitudinal wave, $f_{\mathrm{C} \text { QT1 }}=71.6 \mathrm{MHz}$ and $\Delta f_{\mathrm{QT} 1}=21.6 \mathrm{MHz}$ for the fast quasi-transverse wave, and $f_{\mathrm{C} \text { QT2 }}=69.7 \mathrm{MHz}$ and $\Delta f_{\mathrm{QT2}}=19.7 \mathrm{MHz}$ for the slow quasitransverse wave.

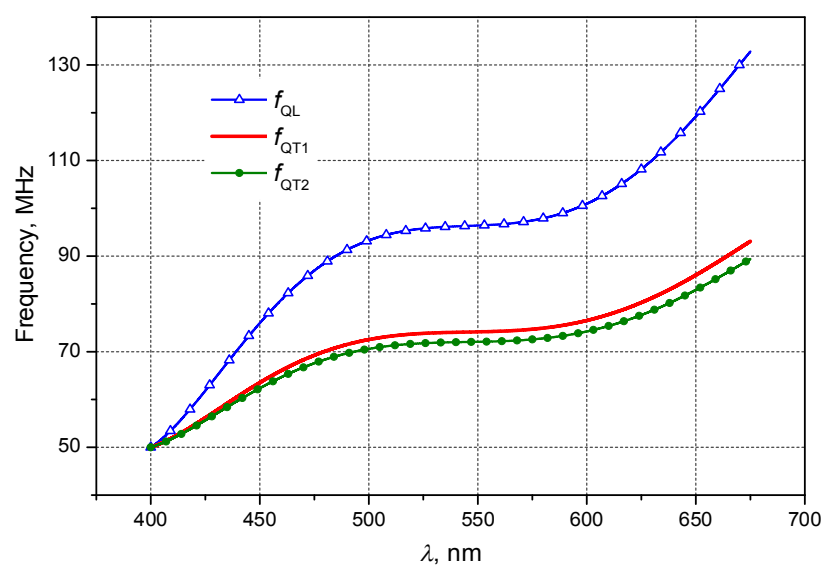

Fig. 3. Dispersion of optic-axis azimuth increment $\Delta X(\lambda)$ for TGS crystals. 
It is worthwhile to note that, under the conditions when the incident laser beam is linearly polarized and slightly divergent and has the polarization parallel to the eigenvector of optical impermeability tensor, the beam reflected from the AO Bragg grating is also linearly polarized due to isotropic diffraction, which is just considered in the present work. However, the divergent diffracted beam is transformed into a vector beam while travelling though the crystal along its optic axis (see, e.g., the analogy with the q-plates [16]). Nonetheless, such a vector beam differs from the beams generated by the liquid crystalline q-plates. Indeed, in the latter case the phase difference is equal to $\pi$ and, moreover, it is homogeneously distributed over the cross section of the q-plate, excluding its centre which has a topological defect. On the other hand, when the diffracted beam propagates along the optic axis in a biaxial crystal, the phase difference is radially changed from zero to a certain value. It means that the diffracted beam in this situation bears a polarization singularity with a radially distributed polarization state.

However, the necessary condition for appearance of the C-point in the centre of this spatial distribution is the incidence of circularly polarized optical beam and accounting for the both types of diffraction, isotropic and anisotropic ones. Notice that the diffracted beam with this distribution of polarization states bears the OV and can be regarded as an optical vector-vortex beam with inseparable polarization and spatial states (see, e.g., Ref. [17]). This AO-diffracted beam should reveal at least the effect of intra-system entanglement between different degrees of freedom, spin and orbit angular momentums in our case $[18,19]$.

\section{Conclusion}

We have analyzed the AO interactions appearing when a divergent diffracted optical beam propagates along one of the optic axes in the biaxial crystals. As a result, we have shown that the diffracted beam transfers an optical vector-vortex field. It has also been demonstrated that the diffracted beam propagating along the optic axis reveals some spatial distribution of polarization states and can be referred to as an optical vector-vortex beam with inseparable polarization and spatial states. It manifests at least the effect of intra-system entanglement between different degrees of freedom, i.e. the spin and orbit angular momentums.

The spatial position of such a beam can be controlled while changing the angle between the optic axes. In its turn, this is achieved by tuning the wavelength of optical radiation and the AW frequency. On the example of the biaxial TGS crystals we have found some quantitative characteristics of the effect. When the initial AW frequency is equal to $50 \mathrm{MHz}$ and the light wavelength changes from 400 to $675 \mathrm{~nm}$, the AW frequency increases up to $\sim 133 \mathrm{MHz}$ for the case of longitudinal acoustic mode, and up to $93 \mathrm{MHz}$ or $89 \mathrm{MHz}$ for the two transverse modes. Hence, it is possible to implement an OV generator on the basis of TGS crystals. Further operation of the OV orientation can also be performed.

\section{References}

1. Kulak G V, 2001. Collinear acousto-optic interaction of light beams near the optic axes of biaxial crystals. J. Appl. Spectrosc. 68: 649-655.

2. Belyi V N, Kulak G V, Krokh G V and Shakin O V, 2016. Collinear acousto-optical transformation of Bessel light beams in biaxial gyrotropic crystals. J. Appl. Spectrosc. 83: 283-287.

3. Kupreychik M I and Balakshy V I, 2018. Peculiarities of acousto-optic interaction in biaxial crystal of alpha-iodic acid. Appl. Opt. 57: 5549-5555.

Ukr. J. Phys. Opt. 2020, Volume 21, Issue 1 
4. Milkov M G, Voloshinov V B, Isaenko L I and Vedenyapin V N, 2018. An experimental study of ultra-wide-band and ultra-wide-aperture non-collinear acousto-optic diffraction in an optically biaxial potassium arsenate titanyl crystal. Moscow Univ. Phys. Bull. 73: 83-88.

5. Krupych O, Vasylkiv Yu, Kryvyy T, Skab I and Vlokh R, 2017. Topological defects of optical indicatrix orientation in optically biaxial crystals. The case of light propagation in the directions close to the optic axes. Ukr. J. Phys. Opt. 18: 131-138.

6. Berry M V, Jeffrey M J and Mansuripur M, 2005. Orbital and spin angular momentum in conical diffraction. J. Opt. A: Pure \& App. Opt. 7: 685-690.

7. O’Dwyer D P, Phelan C F, Rakovich Y P, Eastham P R, Lunney J G and Donegan J F, 2011. The creation and annihilation of optical vortices using cascade conical diffraction. Opt. Express. 19: 2580-2588.

8. Mohammadou S, Mohamadou B and Montemezzani G, 2017. Complex beam shaping by cascaded conical diffraction with intercalated polarization transforming elements. Opt. Express. 25: 25392-25406.

9. Lines M E and Glass A M. Principles and applications of ferroelectrics and related materials. Oxford: Oxford University Press (2001).

10. Romanjuk N A, Kosteckij A M and Viblyi I F, 1976. Dispersion and temperature dependence of refractive indices of pure triglycine sulphate crystals. Ukr. Fiz. Zhurn. 21: 207-209.

11. Hilczer B and Balanicka S, 1973. Influence of defects on the optical behaviour of TGS crystals near the fundamental absorption edge. Phys. Stat. Sol. (a). 19: 717-723.

12. Wood E A and Holden A N, 1957. Monoclinic glycine sulfate: crystallographic data. Acta Cryst. 10: 145-146.

13. Konstantinova V P, Silvestrova I M and Aleksandrov K S, 1959. Obtaining of triglycine sulphate crystals and their physical properties. Kristallografiya. 4: 69-73.

14. Mytsyk B, Demyanyshyn N, Erba A, Shut V, Mozzharov S, Kost Y, Mys O and Vlokh, R. 2017. Piezo-optic and elasto-optic properties of monoclinic triglycine sulfate crystals. Appl. Opt. 56: 9484-9490.

15. Ivanov N R and Zotov V F, 1966. Crystal optic performances of some monoclinic ferroelectrics. Kristallografiya. 11: 924-926.

16. Cardano F, Karimi E, Slussarenko S, Marrucci L, de Lisio C and Santamato E, 2012. Polarization pattern of vector vortex beams generated by q-plates with different topological charges. Appl. Opt. 51: C1-C6.

17. McLaren M, Konrad T and Forbes A, 2015. Measuring the nonseparability of vector vortex beams. Phys. Rev. A. 92: 023833.

18. D’Ambrosio V, Carvacho G, Graffitti F, Vitelli C, Piccirillo B, Marrucci L and Sciarrino F, 2016. Entangled vector vortex beams. Phys. Rev. A. 94: 030304(R).

19. Aiello A, Töppel F, Marquardt C., Giacobino E. and Leuchs G, 2015. Quantum-like nonseparable structures in optical beams. New J. Phys. 17: 043024.

$\overline{\text { Krupych O., Kostyrko M., Adamenko D., Skab I. and Vlokh R. 2020. Tracking of optic axis with }}$ an acousto-optically diffracted beam: generation of vector-vortex beam in triglycine sulfate crystals. Ukr.J.Phys.Opt. 21: 1 - 7. doi: 10.3116/16091833/21/1/1/2020

Анотація. В роботі проаналізовано акустооптичну взаємодію для випадку, коли розбіжний дифрагований оптичний промінь поширюється вздовж однієї з оптичних осей двовісних кристалів. Показано, щзо такий дифрагований промінь має розподіл станів поляризації, 
переносить оптичне векторне вихрове поле $i$ може бути віднесений до оптичного векторного вихрового променя з нероздільною поляризацією та просторовими станами та з щзонайменше внутрішньо-системною заплутаністю між різними ступенями вільності, тобто спіновим $i$ орбітальним моментом імпульсу. Показано, щчо просторовим положенням такого променя можна керувати зміною кута між оптичними осями, налаштовуючи довжину хвилі оптичного випромінювання та частоту акустичної хвилі. На прикладі двовісного кристала тригліичн сульфату було встановлено, щзо для початкової частоти акустичної хвилі 50 МГи при зміні довжини світлової хвилі від 400 нм до 675 нм частота акустичної хвилі зросте приблизно до 133 МГи для поздовжньої акустичної моди $i$ до 93 МГи і 89 МГи для поперечних мод, відповідно. Таким чином, на основі кристала ТГС можна реалізувати генератор оптичних вихорів з керуванням їх просторовим положенням. 